\title{
Modeling of Free Radical Polymerization up to High Conversion. I. A Method for the Selection of Models by Simultaneous Parameter Estimation
}

\author{
N. TEFERA, G. WEICKERT, K. R. WESTERTERP \\ Chemical Reaction Engineering Laboratories, Faculty of Chemical Technology, University of Twente, P.O. Box 217, \\ 7500 AE Enschede, The Netherlands
}

Received 6 October 1995; accepted 5 September 1996

\begin{abstract}
A systematic quantitative method for the selection of models for the highconversion free radical polymerization exhibiting gel and glass effects has been developed. Four representative models were selected from the literature and were compared on the basis of the same experimental data. All models describe the isothermal timeconversion data over the entire conversion range for a single type and loading of initiator well. Models that are not considering the effect of molecular weight of the polymers on the diffusion of macro radicals fail to describe the time-conversion data if the concentration of the initiator varies at the same time. By simultaneous fitting of the conversion and polymerization degree data it was shown that the Marten-Hamielec model and its extended form (Panke-Stickler-Hamielec model) were not able to describe the number average polymerization degree $P n$ at the final conversion, where the glass effect occurs. This occurred because both models neglect the change of the radical efficiency $f$ in this region, which has more effect on $P n$ than the change of the propagation rate coefficient (see part II of this series). (C) 1997 John Wiley \& Sons, Inc. J Appl Polym Sci 63: 1649-1661, 1997
\end{abstract}

Key words: free radical polymerization; high-conversion model; diffusion control

\section{INTRODUCTION}

The physical and mechanical properties of polymers can be strongly affected by the reaction conditions during the production process. One of the main prerequisites for design and optimum operation of a polymerization reactor is, therefore, the knowledge of the process kinetics.

In free radical polymerization three diffusioncontrolled processes can take place beside the ordinary chemical reactions, namely, the cage, gel, and glass effect, which are related to the initiation, termination, and propagation reactions, re-

Correspondence to: K. R. Westerterp.

Contract grant sponsor: Friederich-Naumann Foundation (Germany).

(C) 1997 John Wiley \& Sons, Inc. CCC 0021-8995/97/121649-13 spectively. The cage effect is related to the probability of a primary radical or fragment of initiator molecule to diffuse out of its cage in order to initiate a polymer chain. It enhances the primary radical recombination rate, thus reducing the initiator efficiency $f$. In the past, some investigators considered $f$ to be constant throughout the polymerization, i.e., until very high conversions. In recent years a few investigators disagree on this hypothesis and suggest from an experimental ${ }^{1-6,28,36}$ and theoretical point of view that the radical efficiency reduces drastically in many orders of magnitude with monomer conversions, especially beyond $80 \%$ conversion.

Due to the increase of the viscosity of the reaction medium the motion of macro radicals will be hindered to approach each other for the chemical reaction to occur. This is related to the decrease 
of termination rate, which is known as the gel effect. It accelerates the rate of polymerization and may influence the molecular weight distribution (MWD) of the product in free radical polymerization provided that the termination of macroradicals is not limited by the chain transfer reactions. It can also cause the thermal runaway of a polymerization reactor. If the polymerization is conducted below the glass transition temperature $\left(T_{g}\right)$ of the polymer, the reaction medium becomes glassy before reaching $100 \%$ monomer conversion because of the diffusion-controlled propagation reaction (glass effect).

Numerous attempts have been made to study and model free radical polymerizations up to high conversions. A number of mathematical models have been developed, with different degrees of success in fitting experimental data. These have been recently reviewed by Mita et al. ${ }^{7}$, Kiparissides et al., ${ }^{8}$ and Tefera. ${ }^{9}$ Despite this, a consistent view point on the method of selection of models to be a useful tool for the chemical engineer has not been yet established. The existing models must be evaluated consistently.

This article deals with the modeling of free radical polymerizations up to high conversions from a chemical engineering point of view: for reactor design and scaleup try to reduce the number of free model constants that are to be estimated empirically. In part I we select a model starting from four representative models. In part II an optimal semiempirical model will be developed that covers the changes of all reaction rate parameters over the entire course of the polymerization, and this developed model will be tested in a wide range of temperatures and component concentrations for the radical polymerization of methyl methacrylate (MMA) in bulk, suspension, and solution and with and without chain transfer agents.

\section{THEORETICAL ASPECTS}

\section{Reaction Mechanism}

The reaction mechanism adopted here consists of the known initiation, propagation, termination, and transfer to monomer and to transfer agents steps. The various reactions taking place are

$$
\begin{array}{ll}
\text { 1. Initiation: } & \stackrel{k_{d}}{\rightarrow} 2 R \text { homolytic scission } \\
& R+M \stackrel{k_{i}}{\rightarrow} P_{1} \text { radical initiation }
\end{array}
$$
$a M \stackrel{k_{i a}}{\rightarrow} 2 P_{1} \quad$ thermal initiation
2. Propagation: $\quad P_{j}+M \stackrel{k_{p}}{\rightarrow} P_{j+1}$
3. Transfer:
$P_{j}+M \stackrel{k_{t r, M}}{\rightarrow} M_{j}+P_{1}$
$P_{j}+S \stackrel{\text { transfer to }}{\rightarrow} M_{j}+P_{1}$
transfer to solvent
$P_{j}+C \stackrel{k_{t r, C}}{\rightarrow} M_{j}+P_{1}$
transfer to transfer agent
4. Termination: $P_{j}+P_{k} \stackrel{k_{t c}}{\rightarrow} M_{j+k}$ recombination

$$
P_{j}+P_{k} \stackrel{k_{t d}}{\rightarrow} M_{j}+M_{k}
$$
disproportionation

where $I$ is the initiator, $R$ primary initiator radical, $a$ the reaction order of the thermal initiation, $M$ the monomer, $M_{j}$ dead polymer with degree of polymerization $j, P_{j}$ the corresponding growing polymer radical, and $k$ the relevant rate constants.

\section{Kinetic Modeling}

The development of the kinetic models is based on the application of the method of moments to the mass balances for each of the species existing in the polymerization mix ( see Ray ${ }^{34}$ and Baillagou and Soong ${ }^{35}$ ). For a well-stirred batch reactor according to this procedure and applying the long chain hypothesis ( $\mathrm{LCH}$ ) for the monomer consumption and the quasi-steady-state approximation (QSSA) for the radical concentrations, the following set of algebraic and nonlinear ordinary differential equations are obtained to describe the progress of the reaction and molecular weight developments:

$$
\begin{gathered}
\text { Initiator consumption: } \frac{d\left(I V_{R}\right)}{d t}=-k_{d} I V_{R} \\
\text { Initiation rate: } r_{g}=2 f k_{d} I+2 k_{i a} M^{a}
\end{gathered}
$$

Monomer consumption:

$$
\frac{d\left(M V_{R}\right)}{d t}=-\left(k_{p}+k_{t r, M}\right) M \lambda_{0} V_{R}
$$




$$
\text { Solvent: } \frac{d\left(S V_{R}\right)}{d t}=-k_{t r, S} S \lambda_{0} V_{R}
$$

Chain transfer agent:

$$
\frac{d\left(C V_{R}\right)}{d t}=-k_{t r, C} C \lambda_{0} V_{R}
$$

Moments of the live polymer concentration distributions:

$$
\begin{aligned}
\text { Zeroth } \frac{d\left(\lambda_{0} V_{R}\right)}{d t} & =V_{R}\left(r_{g}-k_{t} \lambda_{0}^{2}\right) \\
\text { First } \frac{d\left(\lambda_{1} V_{R}\right)}{d t} & =V_{R}\left(r_{g}+k_{p} M \lambda_{0}\right. \\
& \left.+T^{*}\left(\lambda_{0}-\lambda_{1}\right)-k_{t} \lambda_{0} \lambda_{1}\right)
\end{aligned}
$$

Second $\frac{d\left(\lambda_{2} V_{R}\right)}{d t}=V_{R}\left(r_{g}+k_{P} M\left(2 \lambda_{1+} \lambda_{0}\right)\right.$

$$
\left.+T^{*}\left(\lambda_{0}-\lambda_{2}\right)-k_{t} \lambda_{0} \lambda_{2}\right)
$$

and applying QSSA for eqs.(6-8) we obtain

$$
\begin{aligned}
& \lambda_{0}=\left(\frac{r_{g}}{k_{t}}\right)^{0.5} \\
& \lambda_{1}=\frac{r_{g}+\left(k_{P} M+T^{*}\right) \lambda_{0}}{T^{*}+k_{t} \lambda_{0}} \\
& \lambda_{2}=\frac{r_{g}+k_{P} M\left(2 \lambda_{1}+\lambda_{0}\right)+T^{*} \lambda_{0}}{T^{*}+k_{t} \lambda_{0}}
\end{aligned}
$$

Moments of the dead polymer concentration distributions:

$$
\begin{gathered}
\text { Zeroth } \frac{d\left(\mu_{0} V_{R}\right)}{d t}=V_{R}\left(T^{*} \lambda_{0}+\left(k_{t d}+0,5 k_{t c}\right) \lambda_{0}^{2}\right) \\
\text { First } \frac{d\left(\mu_{1} V_{R}\right)}{d t}=V_{R}\left(T^{*} \lambda_{1}+k_{t} \lambda_{0} \lambda_{1}\right) \\
\text { Second } \frac{d\left(\mu_{2} V_{R}\right)}{d t}=V_{R}\left(T^{*} \lambda_{2}+k_{t} \lambda_{0} \lambda_{2}+k_{t c} \lambda_{1}^{2}\right)
\end{gathered}
$$

where $T^{*}$ denotes the total transfer term $T^{*}$ $=k_{t r, M} M+k t r, S S+k_{t r, C} C$, and $\lambda_{0}, \lambda_{1}$, and $\lambda_{2}$ are the zeroth, first, and second moment of the growing radicals and $\mu_{0}, \mu_{1}, \mu_{2}$ are the corresponding moments of the dead polymers; $V_{R}$ is the total volume of the reaction mix. The $k$ th moment ( $k$
$=0,1,2)$ of the live and dead polymer concentration distributions are defined as

$$
\begin{array}{ll}
\lambda_{k}=\sum_{k=1}^{\infty} j^{k} P_{j} & \text { for live polymer } \\
\mu_{k}=\sum_{k=1}^{\infty} j^{k} M_{j} & \text { for dead polymer }
\end{array}
$$

To obtain the integral number-average and weight-average degree of polymerization from moments, the following equations can be used:

$$
\begin{aligned}
& \overline{P_{n}}=\frac{\mu_{1}}{\mu_{0}} \\
& \overline{P_{w}}=\frac{\mu_{2}}{\mu_{1}}
\end{aligned}
$$

From the above kinetic and moment equations, the instantaneous number-average and weightaverage degree of polymerizations could be derived; they are given by

$$
\begin{aligned}
P_{n}^{d} & =\frac{\left(T^{*}+k_{t} \lambda_{0}\right) \lambda_{1}}{\left\{T^{*}+\left(k_{t d}+0.5 k_{t c}\right) \lambda_{0}\right\} \lambda_{0}} \\
P_{w}^{d} & =\frac{\left(T^{*}+k_{t} \lambda_{0}\right) \lambda_{2}+k_{t c} \lambda_{1}^{2}}{\left(T^{*}+k_{t}+{ }_{0}\right) \lambda_{1}}
\end{aligned}
$$

Equations (16) and (17), the weight fraction of the reaction component $i, \mathrm{Yi}$, and degree of polymerizations $(P n, P w)$ instead of the concentrations and moments of dead polymers, respectively, can be substituted in to the above equations to give the following final equations for the model calculation:

$$
\begin{aligned}
R_{P} & =k_{P} M \lambda_{0} \frac{M_{M}}{\bar{\rho}} \\
\frac{d Y_{I, i}}{d t} & =-k_{d, i} Y_{I, i} \\
\frac{d Y_{P}}{d t} & =R_{P} \\
\frac{d Y_{S}}{d t} & =-k_{t r, S} Y_{S} \lambda_{0} \\
\frac{d Y_{C}}{d t} & =-k_{t r, C} Y_{C} \lambda_{0} \\
\frac{\mathrm{d} \overline{\mathrm{P}_{n}}}{d t} & =\frac{\overline{P_{n}} R_{P}\left(P_{n}^{d}-\bar{P}_{n}\right)}{P_{n}^{d} Y_{P}}
\end{aligned}
$$


Table I Numerical Values of Parameters Used in Model Calculations

\begin{tabular}{lll}
\hline Parameter & \multicolumn{1}{c}{ Unit } & \multicolumn{1}{c}{ MMA-Polymerization $^{18-20}$} \\
\hline$k_{d}(\mathrm{AIBN})$ & $\mathrm{s}^{-1}$ & $2.8 \times 10^{15} \mathrm{exp}(-15685 / T)$ \\
$f(\mathrm{AIBN})$ & - & 0.43 \\
$k_{i a}$ & $1^{2} \mathrm{~mol}^{-2} \mathrm{~s}^{-1}$ & - \\
$a$ & - & - \\
$k_{p}$ & $1 \mathrm{~mol}^{-1} \mathrm{~s}^{-1}$ & $4.9 \times 10^{5} \mathrm{exp}(-2190 / T)$ \\
$k_{t r, M}$ & $1 \mathrm{~mol}^{-1} \mathrm{~s}^{-1}$ & $2.324 \times 10^{8} \mathrm{exp}(-9218 / T)$ \\
$k_{t}$ & $1 \mathrm{~mol}^{-1} \mathrm{~s}^{-1}$ & $9.8 \times 10^{7} \exp (-353 / T)$ \\
$k_{t d} / k_{t}$ & - & 1 \\
$\rho_{M}$ & $\mathrm{~g} / \mathrm{L}$ & $968-1.15(T-273.15)$ \\
$\rho_{P}$ & $\mathrm{~g} / \mathrm{L}$ & $1.212 \times 10^{3}-0.845(T-273.15)$ \\
$T_{g, M}$ & $\mathrm{~K}$ & 167 \\
$T_{g, P}$ & $\mathrm{~K}$ & 378 \\
$\alpha_{M}$ & $\mathrm{~K}$ & $10^{-3}$ \\
$\alpha_{P}$ & $\mathrm{~K}$ & $4.8 \times 10^{-4}$ \\
\hline
\end{tabular}

$$
\frac{d \bar{P}_{w}}{d t}=\frac{R_{P}\left(R_{w}^{d}-\bar{P}_{w}\right)}{Y_{P}}
$$

In the preceding sets of equations $Y_{i}$ represents the weight fraction of the components, $P_{n}$ and $P_{w}$ the number and weight average degree of polymerization and an overline means integrated value and the superscript $d$ instantaneous value; $M_{M}$ and $\rho$ are the molecular weight of monomer and the density of the polymerization mix, respectively. The number- and weight-average molecular weights are obtained by multiplication of the corresponding polymerization degrees with the molecular weight of monomer.

The simultaneous numerical solution of the above equations through the use of a standard library subroutine (LSODA) has been the base for the development of the parameter estimation program $\mathrm{P} 1$, which is available in program package "PolyReac ." The details of the parameter estimation program P1 and the mathematical methods have been reported elsewhere. ${ }^{33}$

The numerical values of the initial kinetic rate constants and the physical and transport properties of the MMA-PMMA system are reported in Table I.

\section{An Overview of Diffusion-Controlled Models}

In Table II some of the most important models are summarized. Even though the classification of diffusion-controlled models in different groups is not definite due to their hybrid modeling backgrounds, we tried to classify them into different groups according to their theoretical background or to the type of correlations of the rate parameters with specific variables, for example, conversion or viscosity. Almost all models appearing in the literature contain a number of adjustable parameters estimated by fitting model predictions to experimental data. Moreover, critical break points are often introduced to make the onset of different diffusional processes occur during the polymerization.

Models that correlate the rate parameters with the viscosity of the reaction medium, the macroviscosity, may not be applicable for other reaction conditions, because the diffusion limitation of the rate may be caused by the increase of the microviscosity at the reaction sphere, rather than by the macroviscosity. The macroviscosity may not be dependent on the microviscosity in a linear manner. Such a correlation would be useful if the microviscosity of the reaction medium could be used instead of the macroviscosity and its experimental determination were possible.

Models that are based on the concept of reptation after de Gennes, ${ }^{26}$ Ito, ${ }^{19}$ and Tulig et al. ${ }^{18}$ and entanglement idea of O'Driscol ${ }^{20}$ leads to a better understanding of the molecular motion of the macroradicals. These models correlate the termination rate constant with the polymer concentration and with the average chain length of the macroradicals. The model predictions of the conversion-time history up to $70-80 \%$ monomer conversion are good, but above this conversion a large discrepancy between model and experiment develops. Soh and Sundberg ${ }^{23}$ combined the entanglement concept with the free volume theory 
Table II An Overview of Some Important Diffusion-Controlled Models for Free Radical Polymerizations

\begin{tabular}{|c|c|c|c|c|c|}
\hline $\begin{array}{l}\text { Model } \\
\text { Type }\end{array}$ & $\begin{array}{l}\text { Model Concept or } \\
\text { Correlation of Rate } \\
\text { Parameters with }\end{array}$ & Author & $\begin{array}{l}\text { Break } \\
\text { Point }\end{array}$ & $\begin{array}{c}\text { Modeled } \\
\text { Rate } \\
\text { Parameters }\end{array}$ & Monomers \\
\hline 1 & Viscosity & $\begin{array}{l}\text { Hamielec }^{10} \\
\text { Brooks }^{11} \\
\text { Moritz }^{12}\end{array}$ & $\begin{array}{l}\text { yes } \\
\text { yes } \\
\text { yes }\end{array}$ & $\begin{array}{l}k t, f \\
k t \\
k b r\end{array}$ & $\begin{array}{l}\text { ST } \\
\text { MMA } \\
\text { VA }\end{array}$ \\
\hline 2 & $\begin{array}{l}\text { Conversion or weight } \\
\text { fraction of polymer }\end{array}$ & $\begin{array}{l}\text { Ray }^{13} \\
\text { Hamielec }^{14}\end{array}$ & $\begin{array}{l}\text { yes } \\
\text { yes }\end{array}$ & $\begin{array}{l}k t \\
k b r, C t r m\end{array}$ & $\begin{array}{l}\text { ST, MMA } \\
\text { ST }\end{array}$ \\
\hline & Polymer & $\begin{array}{l}\text { Gilbert }^{15} \\
\text { Weickert }^{16} \\
\text { Buback }^{17}\end{array}$ & $\begin{array}{l}\text { yes } \\
\text { no } \\
\text { no }\end{array}$ & $\begin{array}{l}k t, k p \\
k t, f \\
k t, k p\end{array}$ & $\begin{array}{l}\text { MMA } \\
\text { MMA, ST } \\
\text { MMA, BA }\end{array}$ \\
\hline 3 & Reptation theory & $\begin{array}{l}\text { Tulig } \\
\text { Ito }^{19}\end{array}$ & $\begin{array}{l}\text { yes } \\
\text { yes }\end{array}$ & $k t$ & $\begin{array}{l}\text { MMA, ST } \\
\text { MMA }\end{array}$ \\
\hline $\begin{array}{l}4 \\
5\end{array}$ & $\begin{array}{l}\text { Entanglement } \\
\quad \text { concept } \\
\text { Free volume theory }\end{array}$ & $\begin{array}{l}\text { O'Driscoll } \\
\text { Hamielec }^{21} \\
\text { Ray }^{22} \\
\text { Soh }^{23} \\
\text { Soong }^{24} \\
\text { Kiparissides }^{25}\end{array}$ & $\begin{array}{l}\text { yes } \\
\text { yes } \\
\text { yes }\end{array}$ & $\begin{array}{l}k t \\
k t, k p \\
k t, k p \\
k t, k p \\
k t, k p \\
k t, k p, f\end{array}$ & $\begin{array}{l}\text { MMA } \\
\text { MMA, ST } \\
\text { MMA, ST } \\
\text { MMA, ST } \\
\text { EMA, VA } \\
\text { MMA } \\
\text { MMA, ST }\end{array}$ \\
\hline
\end{tabular}

and proposed a new form of chain length dependence of the termination rate constant. At the same time they divided the conversion range into four parts, thus introducing critical transition points. In each region they define a distribution function that characterizes the chain length dependence of the termination rate constant. Some of the model parameters had to be determined by trial and error fitting, others could be evaluated separately. Their model was tested for six different monomers. Its applicability for the design of a polymerization reactor is limited because of its complexity and undefined temperature and concentration dependence of the model parameters. In the region of final conversion, the difference between the results of model prediction and experiment is also too large.

In the models of Soong et al. ${ }^{24}$ and Buback ${ }^{17}$ the diffusion effects are viewed as an integral part of the termination and propagation reactions from the beginning until the end of the polymerization. This eliminates the need for the use of a critical break point, the sudden introduction of diffusion effects, and the associated segmentation of model in different parts. Both models do not consider the change of the radical efficiency. In the Buback model the reaction diffusion is included, while in the Soong model the dependence of the transla- tional diffusion of the macroradicals on the initial concentration of the initiator and the total radical concentration is adopted.

Some authors correlated high conversion kinetics with the initial concentration of the initiator. The application of diffusion-controlled models, which contain the initial concentration of the initiator, on other polymerization conditions such as in a semibatch polymerization with initiator feeding may not hold true (see, e.g., models of Soong et al. and Moritz ${ }^{12}$ ). As pointed out by Achilias and Kiparissides, ${ }^{25}$ their model is based on that of Soong et al. and does not contain adjustable parameters. They reported in 1992 also that their model was extended by modeling the change of radical efficiency during the polymerization and that it also incorporates the reaction diffusion. All parameters in their models have a clear physical meaning and can be evaluated in terms of physical and transport properties of the reacting species. Their aim to develop such physically meaningful models seems to be real and progressive. But the comparison of model predictions with experimental results shows it to be unsatisfactory, especially at very high conversions. The authors claim that this discrepancy be due to the nonisothermal conditions of the experiments without any further proof. According to our knowledge, 
Table III Model Equations for the Gel and Glass Effect

$$
\begin{aligned}
& \text { Weickert model }^{16} \\
& f=f_{0}\left[1-\left(\frac{Y_{P}}{Y_{P g}}\right)^{2}\right]^{g 2} \quad k_{t}=k_{t 0}\left(1+g 1 Y_{P}^{1.5}\right)^{2} \exp \left(-2 g 1 Y_{P}^{1.5}\right) \quad Y_{p g}=\frac{1}{A+\frac{B}{T_{c}-T_{g}}}
\end{aligned}
$$

Model parameters, g1, g2

Buback model $^{17}$

$$
\begin{array}{cc}
k_{P}=\frac{1}{\frac{1}{k_{p 0}}+\frac{1}{k_{P D}^{0}}\left[\exp \left(c_{\eta} X\right)-1\right]} & k_{t}=\frac{1}{\frac{1}{k_{t 0}-K_{R D 0}}+\frac{1}{k_{T D}^{0}}\left[\exp \left(c_{\eta} X\right)-1\right]}+K_{R D} \\
K_{R D}=C_{R D} K_{P} M_{0}(1-X) & K_{R D 0}=C_{R D} K_{P 0} M_{0} .
\end{array}
$$

Model parameters, g1 $=k_{T D}^{0}$, g2 $=c_{\eta}$, g3 $=C_{R D}, \mathrm{~g} 4=k_{P D}^{0}$

Marten-Hamielec and Panke-Stickler-Hamielec model ${ }^{21,27}$

$$
\begin{aligned}
& K_{3}=K_{3 c r 1}=M_{w c r 1}^{0,5} \exp \left(\frac{A}{v_{f c r 1}}\right) \\
& k_{t}=k_{t 0} \cdot K_{3 c r 1} \frac{M_{w c r 1}^{1,25}}{M_{w}^{1,75}} \exp \left(\frac{-A}{v_{f}}\right)+C_{R D} k_{P} M, \quad \text { vf }<v_{f c r 1} \\
& k_{P}=k_{P 0} \exp \left\{-B\left(\frac{1}{v_{f}}-\frac{1}{v_{f c r 2}}\right)\right\}, \mathrm{B}=1, \quad \text { of }<v_{f c r 2}
\end{aligned}
$$

Model parameters, g1 $=K_{3 c r}$, g2 $=A$, g3 $=v_{f c r 2}, C_{R D}=0$ (Marten-Hamielec model), g1 $=K_{3 c r}, \mathrm{~g} 2=A$, g3 $=v_{f c r 2}, \mathrm{~g} 4=C_{R D}$ (Panke-Stickler-Hamielec model)

Note that the initial conditions are inserted in the Buback model.

this may be due to additional parameters in the model that should be obtained from different experimental data. These correlations may not hold true for the conditions in which the polymerization was conducted. Therefore, from a chemical engineering point of view such extensive efforts of modeling may be useful if one reaches at least equal qualitative and quantitative agreement between model and experimental results as the semiempirical models.

\section{Model Selection Methods}

Among the numerous published high conversion models four were selected to demonstrate the model selection strategy. These are: the Weickert model, ${ }^{16}$ with two adjustable parameters; the Buback model, ${ }^{17}$ with four adjustable parameters; the Marten-Hamielec model, ${ }^{21}$ with three adjustable parameters; and the PankeStickler-Hamielec model, ${ }^{27}$ with four adjustable parameters.
Both models 1 and 2 represent models that do not comprise the influence of the molecular weight of neither the active nor the dead polymers, and they do not introduce break points, while the last two include the influence of the molecular weight of the dead polymers and have two break points. The model equations are summarized in Table III.

We propose the following steps as a useful procedure to evaluate or compare models for high conversion polymerizations. As an example we use the bulk polymerization of MMA with AIBN in which the conversion and degree of polymerization were measured.

1. Choose a minimum experimental data set with at least one objective variable and one control variable, for example, control variable: initiator concentration and objective variable: conversion.

2. Estimate the model parameters by using a single experimental data set conducted with different control variables in order to 
(a)

(b)
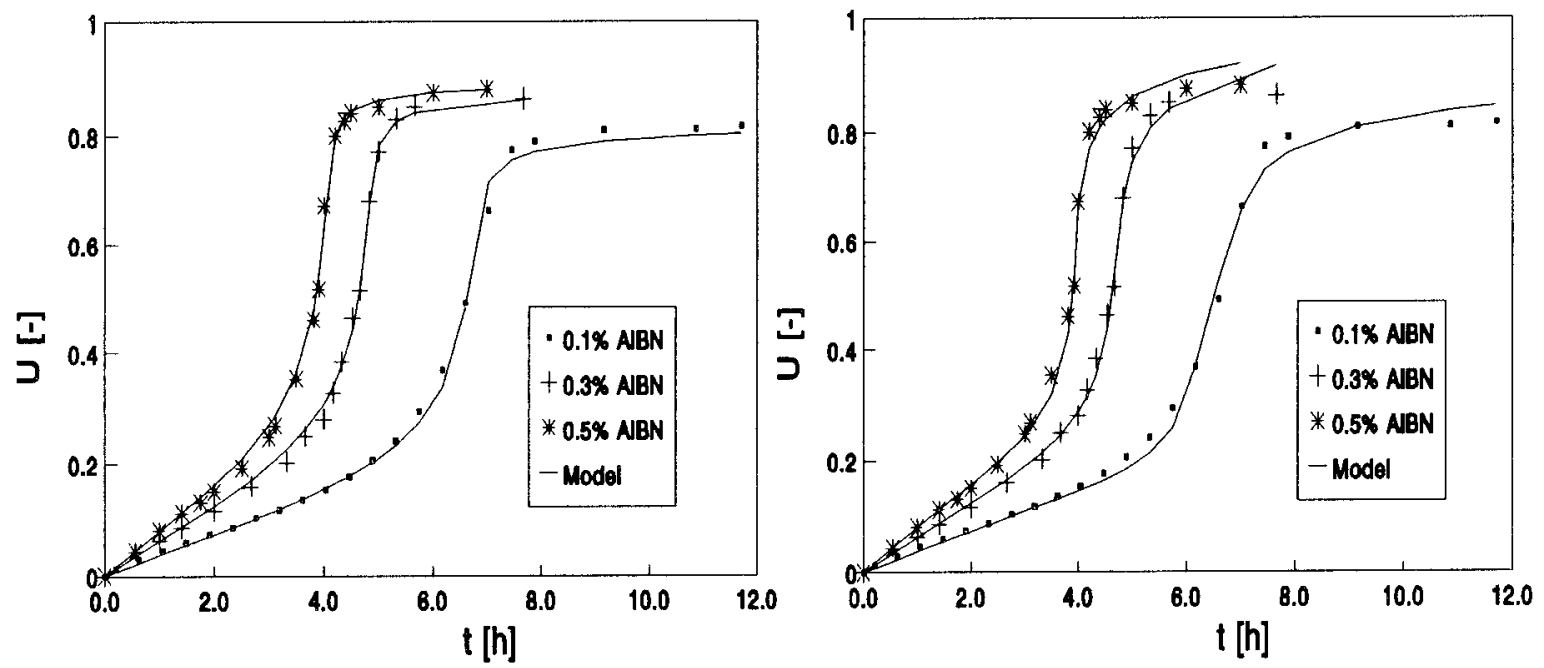

c)

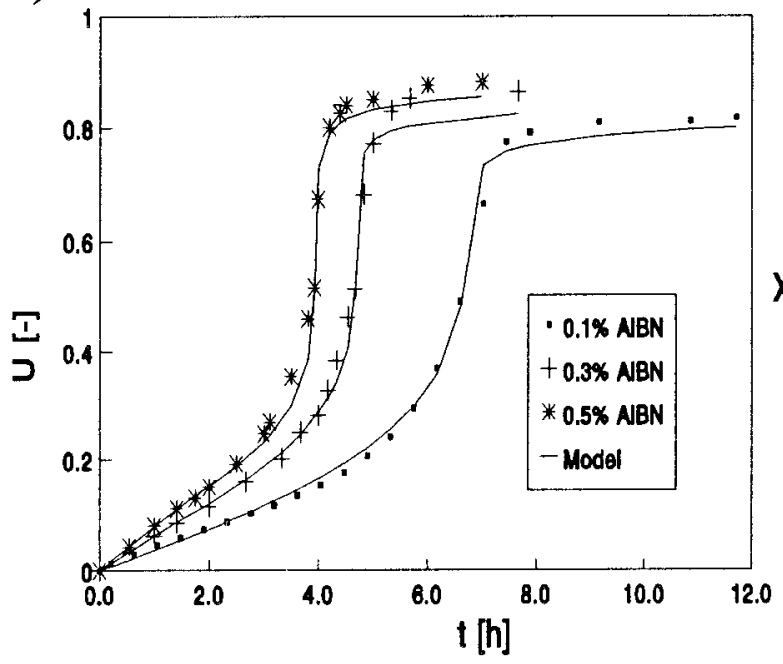

(d)

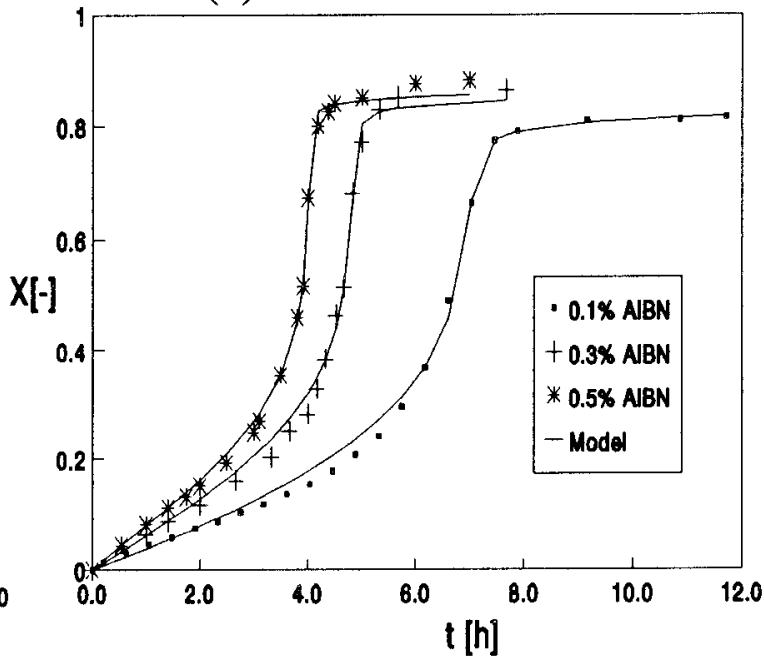

Figure 1 Bulk polymerization of MMA with $\mathrm{AIBN}$ at $50^{\circ} \mathrm{C}$; model comparison by estimation of model parameters from single data fitting (a) Weickert model, (b) Buback model, (c) Marten-Hamielec model, (d) Panke-Stickler-Hamielec model.

see the qualitative applicability of the model, separately. Register the confidence interval of each parameter and the sum of the least square errors (SLSE), $F_{E, i}$, for each fitting, for example, time-conversion data set with different initiator loadings.

3. Estimate the model parameters by using all experimental data under step 2 simul- taneously, register the confidence interval of the model parameter and the sum of the least square errors, $F_{G}$, for example, timeconversion data with initial initiator loadings $0.1,0.3$, and $0.5 \mathrm{wt} \%$.

We suggest a possible quantitative evaluation of the model flexibility that is given in eq. (25). The "model flexibility," $M_{f}$, to- 
Table IV Bulk Polymerization of MMA with AIBN at 50 ${ }^{\circ}$; Model Comparison by Estimation of Model Parameters from Single Data Fitting

\begin{tabular}{|c|c|c|c|c|c|}
\hline Model & $\begin{array}{l}\text { Initiator Loading } \\
\text { (wt \%) }\end{array}$ & Parameter & Value & $\begin{array}{c}\text { Confidence Interval } \\
(95 \%)(\%)\end{array}$ & $\begin{array}{l}\text { Sum of the Least } \\
\text { Square Errors }\end{array}$ \\
\hline \multirow[t]{6}{*}{ Weickert } & \multirow[t]{2}{*}{0.1} & g1 & 30.752 & 2.29 & \multirow[t]{2}{*}{$5.756 \times 10^{-3}$} \\
\hline & & g2 & 27.471 & 5.86 & \\
\hline & \multirow[t]{2}{*}{0.3} & g1 & 21.625 & 2.26 & \multirow[t]{2}{*}{$2.714 \times 10^{-3}$} \\
\hline & & g2 & 14.208 & 7.36 & \\
\hline & \multirow[t]{2}{*}{0.5} & g1 & 19.091 & 3.18 & \multirow[t]{2}{*}{$4.96 \times 10^{-3}$} \\
\hline & & g2 & 11.222 & 9.36 & \\
\hline \multirow[t]{12}{*}{ Buback } & \multirow[t]{4}{*}{0.1} & $\ln \mathrm{g} 1$ & 23.282 & 16.61 & \multirow[t]{4}{*}{$8.633 \times 10^{-3}$} \\
\hline & & g2 & 36.888 & 50.32 & \\
\hline & & g3 & 34.149 & 56.40 & \\
\hline & & $\ln \mathrm{g} 4$ & 31.662 & 47.62 & \\
\hline & \multirow[t]{4}{*}{0.3} & $\ln \mathrm{g} 1$ & 21.793 & 8.2 & \multirow[t]{4}{*}{$7.046 \times 10^{-3}$} \\
\hline & & g2 & 23.786 & 27.83 & \\
\hline & & g3 & 9.117 & 25.27 & \\
\hline & & $\ln \mathrm{g} 4$ & 22.084 & 37.77 & \\
\hline & \multirow[t]{4}{*}{0.5} & $\ln \mathrm{g} 1$ & 22.468 & 3.0 & \multirow[t]{4}{*}{$6.694 \times 10^{-3}$} \\
\hline & & g2 & 24.395 & 9.79 & \\
\hline & & g3 & 0.653 & 27.89 & \\
\hline & & $\ln \mathrm{g} 4$ & 21.165 & 6.86 & \\
\hline \multirow[t]{9}{*}{$\mathrm{MH}$} & \multirow[t]{3}{*}{0.1} & $\ln \mathrm{g} 1$ & 13.4633 & 12.37 & \multirow[t]{3}{*}{$8.275 \times 10^{-3}$} \\
\hline & & g2 & 1.1083 & 22.63 & \\
\hline & & g3 & 0.0738 & 18.30 & \\
\hline & \multirow[t]{3}{*}{0.3} & $\ln \mathrm{g} 1$ & 14.5977 & 6.61 & \multirow[t]{3}{*}{$15.948 \times 10^{-3}$} \\
\hline & & g2 & 1.2541 & 12.39 & \\
\hline & & g3 & 0.0734 & 16.32 & \\
\hline & \multirow[t]{3}{*}{0.5} & $\ln \mathrm{g} 1$ & 16.9592 & 2.12 & \multirow[t]{3}{*}{$15.128 \times 10^{-3}$} \\
\hline & & g2 & 1.559 & 3.53 & \\
\hline & & g3 & 0.0839 & 9.17 & \\
\hline \multirow[t]{12}{*}{ PSH } & \multirow[t]{4}{*}{0.1} & $\ln \mathrm{g} 1$ & 12.49716 & 8.65 & \multirow[t]{4}{*}{$5.4980 \times 10^{-3}$} \\
\hline & & g2 & 0.96063 & 18.22 & \\
\hline & & g3 & 0.05083 & 15.32 & \\
\hline & & g4 & 8.04233 & 230 & \\
\hline & \multirow[t]{4}{*}{0.3} & $\ln \mathrm{g} 1$ & 12.39309 & 13.64 & \multirow[t]{4}{*}{$6.55270 \times 10^{-3}$} \\
\hline & & g2 & 0.942998 & 29.24 & \\
\hline & & g3 & 0.040233 & 23.59 & \\
\hline & & $\mathrm{g} 4$ & 6.5183 & 352 & \\
\hline & 0.5 & $\ln \mathrm{g} 1$ & 12.41453 & 10.19 & $3.4413 \times 10^{-3}$ \\
\hline & & g2 & 0.94144 & 21.72 & \\
\hline & & g3 & 0.038386 & 25.46 & \\
\hline & & $\mathrm{g} 4$ & 2.6902 & 517 & \\
\hline
\end{tabular}

wards a single control or operating variable, for example, initial initiator concentration, is defined as the ratio of the sum of SLSE of the single parameter adjustment, $F_{E, i}$, and the SLSE of the simultaneous parameter adjustment, $F_{G}$.

$$
M_{f}=\frac{\sum_{i} F_{E, i}}{F_{G}}
$$

4. Estimate the model flexibility, $M_{f}$, of the models from step 2 and 3 . Models that have a high model flexibility and a minimum sum of the least square errors may be examined in the next selection steps.

5. Is there any other objective function for the given experiment to be adjusted [e.g., new objective function: degree of polymerizations $\left.\left(P_{n}, P_{w}\right)\right]$ ? If yes, repeat step 1 to 4 and compare the model flexibility of every model. 


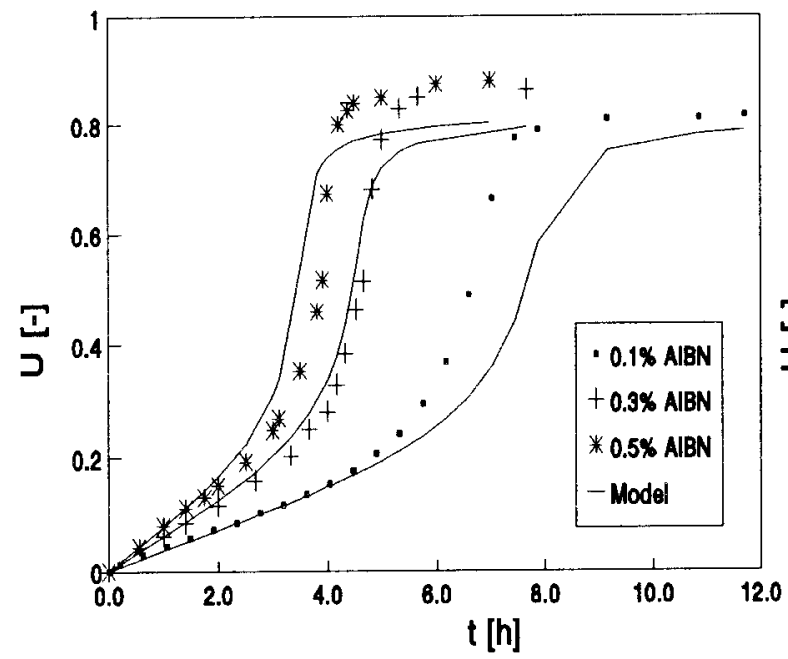

c)

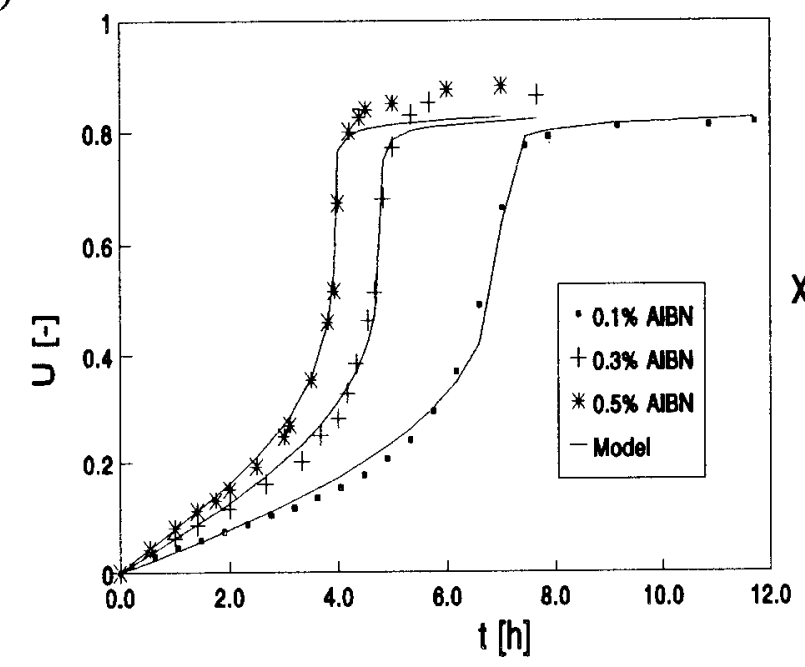

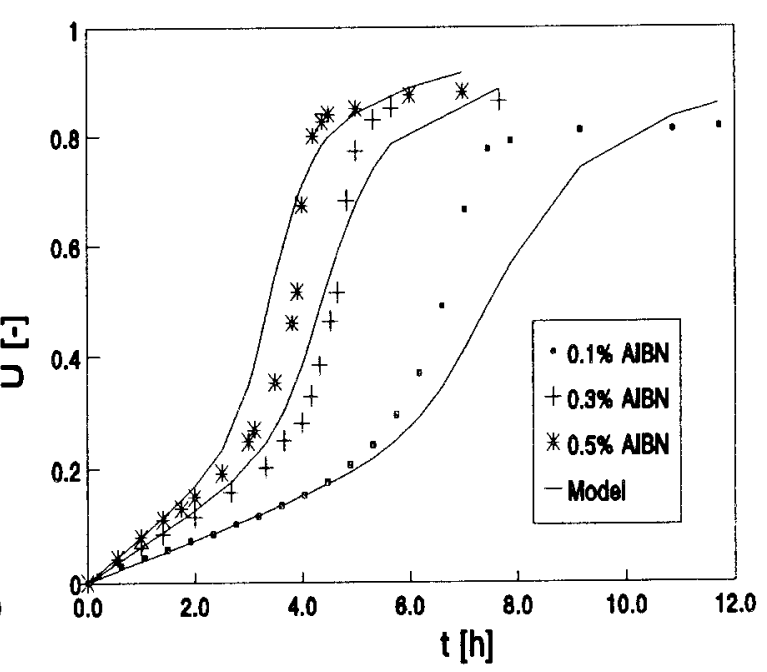

(d)

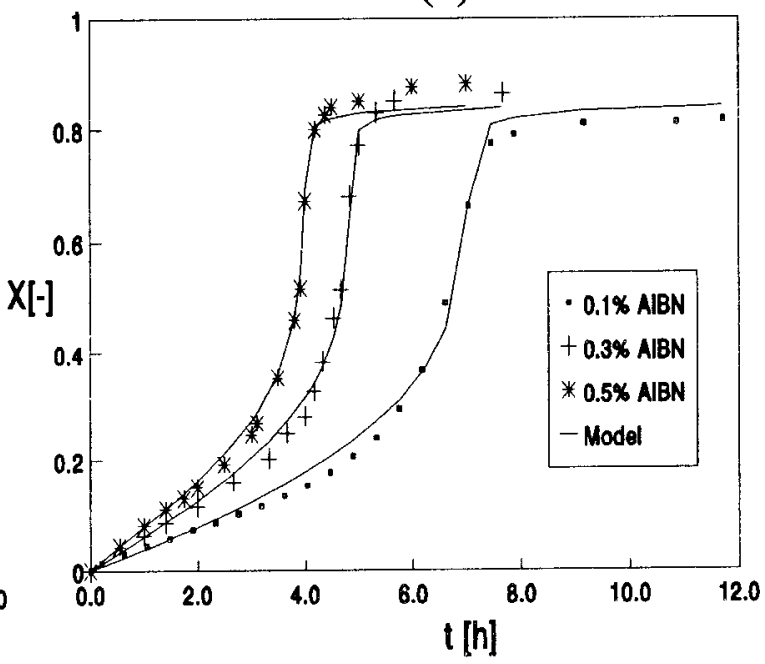

Figure 2 Bulk polymerization of MMA with $\mathrm{AIBN}$ at $50^{\circ} \mathrm{C}$; model comparison by estimation of model parameters from the whole data set: (a) Weickert model, (b) Buback model, (c) Marten-Hamielec model, (d) Panke-Stickler-Hamielec model.

6. Estimate the model parameters from isothermal data and compare them with nonisothermal experiments.

7. Determine the sensibility of model parameters.

8. Examine the applicability of the selected model to other polymerization conditions, for example, solution, suspension, bulk, as well as emulsion polymerization with variable type and concentration of initiator and chain transfer agents.
We next demonstrate these model selection steps using the above four mentioned models.

\section{RESULT AND DISCUSSION}

For the model selection the experimental data of the bulk polymerization of MMA with AIBN at $50^{\circ} \mathrm{C}^{31,32}$ (only conversion data) and at $70^{\circ} \mathrm{C}^{31}$ ( conversion and degree of polymerization $\left(P_{n}, P_{w}\right)$ data) were selected. 
Table V Bulk Polymerization of MMA with AIBN at 50 ${ }^{\circ}$; Model Comparison by Estimation of Model Parameters from the Whole Data Set

\begin{tabular}{|c|c|c|c|c|c|}
\hline & $\begin{array}{c}\text { Model } \\
\text { Parameter }\end{array}$ & Value & $\begin{array}{c}\text { Confidence Interval } \\
(95 \%)(\%)\end{array}$ & $\begin{array}{l}\text { Sum of the Least } \\
\text { Square Errors }\end{array}$ & $M f$ \\
\hline \multirow[t]{2}{*}{ Weickert } & g1 & 26.60764 & 9.35 & 0.5314 & 0.025 \\
\hline & g2 & 23.91443 & 21.73 & & \\
\hline \multirow[t]{4}{*}{ Buback } & $\ln \mathrm{g} 1$ & 20.818 & 13.75 & 0.4466 & 0.05 \\
\hline & g2 & 22.698 & 57.75 & & \\
\hline & g3 & 126.64 & 60.07 & & \\
\hline & $\ln \mathrm{g} 4$ & 23.1436 & 46.84 & & \\
\hline \multirow[t]{3}{*}{ Marten-Hamielec } & $\ln \mathrm{g} 1$ & 12.367 & 0.18 & 0.0460 & 0.855 \\
\hline & g2 & 0.9358 & 0.52 & & \\
\hline & g3 & 0.05892 & 4.94 & & \\
\hline \multirow[t]{4}{*}{ PSH } & $\ln \mathrm{g} 1$ & 12.21042 & 0.27 & 0.0276 & 0.561 \\
\hline & g2 & 0.91419 & 0.52 & & \\
\hline & g3 & 0.044361 & 8.44 & & \\
\hline & $\mathrm{g} 4$ & 2.9403 & 86.80 & & \\
\hline
\end{tabular}

\section{Result of the Parameter Estimation from Time-Conversion Data}

In Figure 1, experimental results on conversion for the AIBN-initiated free radical polymerization of MMA at $50^{\circ} \mathrm{C}$ with variable initiator loadings are compared with model predictions. As can be seen, there is good agreement between experimental and predicted results for all models although at final conversions a small quantitative discrepancy is observed. Table IV summarizes the values of the fitted model parameters with their confidence intervals and the sum of the least square errors (SLSE) for each model respective of each experiment. In all cases the SLSE lies in the same order of magnitude. The model parameters of Buback (g3,g4) and Weickert (g1,g2) depend on the initiator concentration as expected because both models have no chain length dependencies. On the other hand, the model parameters of both Panke et al. (PSH) and Marten et al. (MH) models show no such dependence. It is apparent from the results of Table IV that in case of PSH model we obtain a lower SLSE than that of the $\mathrm{MH}$ model. This is because the former accounts for the reaction diffusion, which is an important additional elementary process step.

In the next selection step, the three experimental data sets above with $0.1,0.3$, and $0.5 \mathrm{wt} \%$ of AIBN were taken and the model parameters adjusted simultaneously. The results are given in Figure 2 as well as in Table V. The variation of initiator concentration should reduce the effect of the autocorrelation between model parameters. It is obvious from the Figure $2(\mathrm{a}-\mathrm{d})$ that models that do not take into account the degree of polymerization of the active or dead polymers, the models of Weickert and Buback, do not describe the experiments well. In order to get a better agreement between experiment and model in such cases, one should correlate the model parameters with the degree of polymerization. This demands higher efforts and leads to other types of models, such as the Marten et al. or Panke et al. models.

The last column of Table V compares the model flexibilities. The first two have larger sum of the least square errors and a lower $M_{f}$ towards the initial concentration of the initiator as expected. Both of them should be dropped at this selection step because they can not fulfill the requirements of an optimal model. The last two show higher model flexibility and a minimum sum of the least square errors. Even though the last two models show a difference in their SLSE and $M_{f}$, both will be examined in the next selection step because here the degree of polymerization will be included. These models embody the weight-average molecular weight of the dead polymer. Because both models differ only by the inclusion of the reaction diffusion term, the next step may also give us an insight on the importance of the reaction diffusion term.

\section{Result of the Parameter Estimation from Time-Conversion and Time-Degree of Polymerization Data}

We next investigate the applicability of both the $\mathrm{MH}$ and PSH models by simultaneous parameter 
(a)

(b)
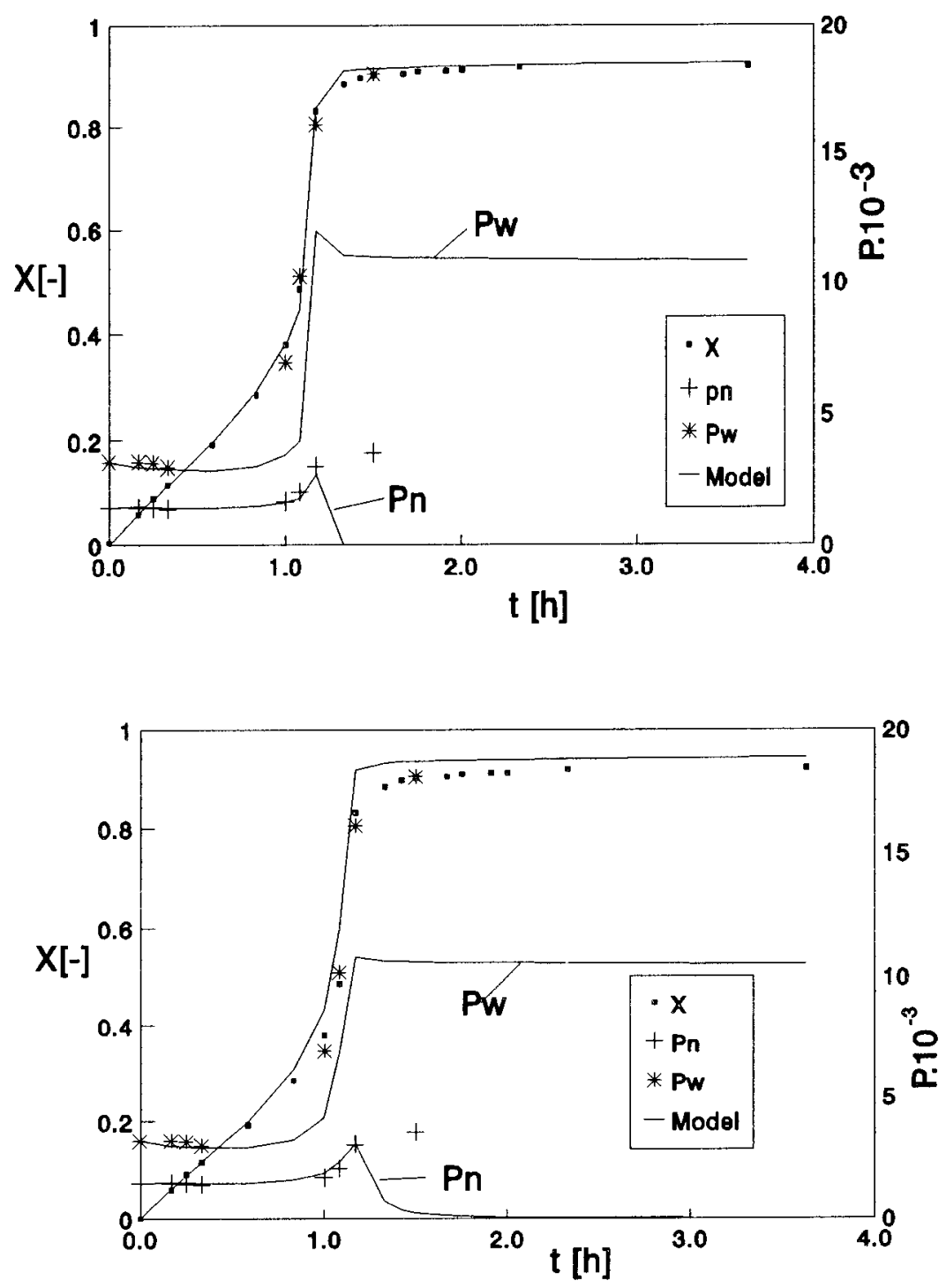

Figure 3 Bulk polymerization of MMA with 0.3 wt $\% \mathrm{AIBN}$ at $70^{\circ} \mathrm{C}$; model comparison by simultaneous parameter estimation from conversion $(\mathrm{X})$, number average $(P n)$ and weight average $(P w)$ degree of polymerization data: (a) Marten-Hamielec model, (b) Panke-Stickler-Hamielec model.

estimation from a single experimental data set. In Figure 3( $\mathrm{a}-\mathrm{b})$ predicted results for conversion, $P_{n}$ and $P_{w}$ are compared to the corresponding experimental values for the polymerization of MMA with $0.3 \mathrm{wt} \%$ AIBN at $70^{\circ} \mathrm{C}$. The model parameters were determined by a simultaneous parameter estimation from conversion and average degrees of polymerization, $P_{n}$ and $P_{w}$. In general, there is for both models a good agreement between predicted and experimental values of the conversion. There is also a good agreement be- tween experimental and predicted values of $P_{n}$ and $P_{w}$ for the initial and intermediate polymerization range. But in both cases we observe a discrepancy between the predicted and experimental values of $P_{n}$ and $P_{w}$. The simulated value of $P_{n}$ especially converges to a very low value at very high conversions. Such a low value of $P_{n}$ may be associated with a high concentration of radicals and the production of oligomers. This is due to the neglect of the change of the radical efficiency in the glass effect region. The simulated radical 


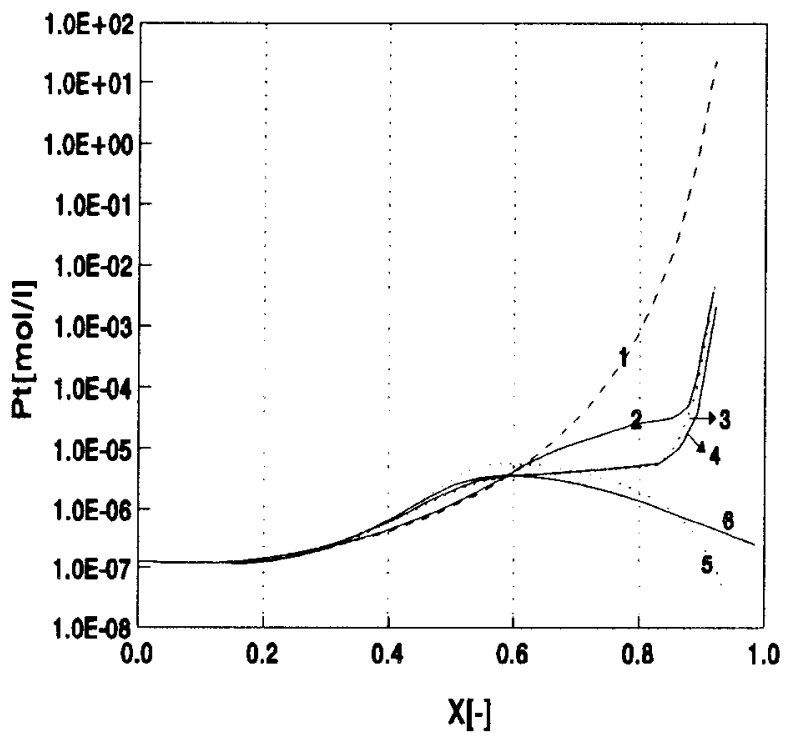

Figure 4 Simulated radical concentrations $P t$ as a function of monomer conversions. Marten-Hamielec model (1) with QSSA, (2) without QSSA, PSH-model, (3) with QSSA, (4) without QSSA. This work, (5) with QSSA, (6) without QSSA (see part II).

concentrations in both models with and without the QSSA assumption are shown in Figure 4. We obtain unrealistic values for the total radical concentration, for example, at monomer conversions of $90,91.5$, and $92 \%$ the corresponding radical concentration are $1.8,13$, and $24 \mathrm{~mol} / \mathrm{L}$, which exceeds the maximum attainable radical concentration of twice the initial concentration of the initiator, in this case $0.03 \mathrm{~mol} / \mathrm{L}$.

\section{CONCLUSIONS}

In the literature a number of mathematical models for the radical polymerization up to high conversion are available. A consistent method with a minimum effort for the selection of a diffusioncontrolled models has been established using four representative models. For the demonstration purposes, the polymerization of MMA with AIBN were used. All models describe the isothermal time-conversion data well over the entire conversion range for a single type and loading of initiator. Models that do not consider the effect of the molecular weight of polymers on the diffusion of macro radicals fail to describe the time-conversion data correctly if the concentration of the initiator varies at the same time. By simultaneous fitting of the conversion and polymerization degree data it was shown that the Marten-Hamielec model and its extended form (Panke-Stickler-Hamielec model) were not able to describe the number average polymerization degree $P_{n}$ at the final conversion, where the glass effect occurs. This phenomenon occurred because both models neglect the change of the radical efficiency $f$ in this region, which has a great influence in the region of high conversion. In part II of this series, a semiempirical model will be developed that comprises the change of all reaction rate parameters over the entire course of polymerization.

Financial support from the Friedrich-Naumann Foundation (Germany) is greatly appreciated.

\section{REFERENCES}

1. J. Shen, Y. Tian, G. Wang, and M. Yang, Makromol. Chem., 192, 2669 (1991).

2. S. Zhu, Y. Tian, A. E. Hamielec, and D. R. Eaton, Polymer, 31, 154 (1990).

3. R. Sack, G.-V. Schulz, and G. Mayerhoff, Macromolecules, 21(12), 3345 (1988).

4. E. Schmid, dissertation, Universität Göttingen (1992).

5. G. Weickert and N. Tefera, Lecture on IUPAC Working Party, Nancy, Nov. 1991, and in 4th International Workshop on Polymer Reaction Engineering, K.-H. Reichert and H.-U. Moritz, Eds., Verlag Chemie, Weinheim, 1992, p. 115.

6. N. Tefera, G. Weickert, R. Bloodworth, and J. Schweer, Macromol. Chem. Phys., 195, 3067 (1994).

7. I. Mita and K. Horie, JMS-Rev. Macromol. Chem. Phys., C27(1), 91 (1987).

8. D. Achilias and C. Kiparissides, J. Appl. Polym. Sci., 35, 1303 (1988).

9. N. Tefera, Ph.D. thesis, University of Twente (1995).

10. J. H. Duerksen and A. E. Hamielec, J. Polym. Sci., C25, 155 ( 1968).

11. B. W. Brooks, Proc. R. Soc. Lond., A357, 1311 (1977).

12. H.-U. Moritz, Dissertation B, TU Berlin (1981).

13. W. H. Ray and R. Jaisinghani, Chem. Eng. Sci., 32, 811 (1977).

14. A. W. Hui and A. E. Hamielec, J. Appl. Polym. Sci., 16, 749 (1972).

15. M. J. Ballard, R. G. Gilbert, and D. H. Napper, J. Polym. Sci., 32, 3225 (1984); Macromolecules, 19, 1303 (1986).

16. G. Weickert, Dissertation B, TH-Merseburg (1982).

17. M. Buback, Macromol. Chem., 191, 1575 (1990). 
18. T. J. Tulig and M. V. Tirrell, Macromolecules, 15, 459 (1982).

19. K. Ito, Polym. J., 12(8), 499 (1980); 13(8), 127 (1981); 16(10), 761 (1984).

20. J. N. Cardenas and K. F. O’Driscoll, J. Polym. Sci., Polym. Chem. Ed., 14, 883 (1976); 15, 1883, 2097 (1977).

21. F. L. Marten and A. E. Hamielec, Am. Chem. Soc., Symp. Ser., 104, 43 (1979).

22. A. D. Schmidt and W. H. Ray, Chem. Eng. Sci., 36, 1401 (1981).

23. S. K. Soh and D. C. Sundberg, J. Polym. Sci., Polym. Chem. Ed., 20, 1299, 1315, 1331, 1345 (1982).

24. W. Y. Chiu, G. M. Carratt, and D. S. Soong, Macromolecules, 16, 348 (1983).

25. D. Achilias and C. Kiparissides, Macromolecules, 25, 3739 (1992).

26. P. G. deGennes, J. Chem. Phy., 55, 572 (1971); 76, 3322 (1982).
27. D. Panke. M. Stickler, and A. E. Hamielec, J. Polym. Sci., Polym. Chem., 22, 2243 (1984).

28. J. Shen, G. Wang, Y. Zheng, and M. Yang, Macromol. Chem. Macromol. Symp., 63, 105 (1992).

29. K. Horie, I. Mita, and M. Kabe, J. Polym. Sci., Chem., A1(6), 2663 (1968).

30. K. Mahabadi and K. F. O'Driscoll, J. Macromol. Sci., Chem., A11(5), 967 (1977).

31. S. T. Balke and A. E. Hamielec, J. Appl. Polym. Sci., 17, 905 (1973).

32. D. Panke and Röhm AG, Persoenliche Daten.

33. G. Weickert, Modellierung von Polymerisationsreaktoren, Springer, Berlin, 1996.

34. W. H. Ray, J. Macromol. Sci. Rev., C8, 1 (1972).

35. P. E. Baillagou and D. S. Soong, Chem. Eng. Sci. 40, 75, 87 ( 1985 ).

36. G. T. Russell, D. H. Napper, and R. G. Gilbert, Macromolecules, 21, 2141 (1988). 